\title{
SOBRE LA ÉTICA DE UNA MORATORIA EN EDICIÓN GENÉTICA HUMANA*
}

\section{ON THE ETHICS OF A MORATORIUM ON HUMAN GENE EDITING}

\author{
Robert T. HALL ${ }^{* *}$ \\ María de Jesús Medina ARellano***
}

\section{Resumen:}

Este trabajo analiza las implicaciones sociales de la moratoria propuesta en la revista Nature por científicos sobre edición genética en la línea germinal. Afirmamos que la investigación no se debe basar en consensos de opinión pública, sino en evidencia científica. La investigación en ciencia básica en animales podría ser suficiente, para después, investigar en embriones humanos, este es un juicio moral, pero se basa en evidencia y debe ser tomado por personas que entienden la ciencia, no por la opinión pública. El punto de una moratoria es el de avanzar de manera cautelosa, pero no el de limitar el progreso, por tanto, las implicaciones sociales que apunta dicha moratoria son limitantes y perpetúan estigma sobre la innovación en ciencia.

\section{Palabras clave:}

Edición genética, investigación en la línea germinal, moratoria, consenso, opinión pública.

* Artículo recibido el 24 de enero de 2020 y aceptado para su publicación el 10 de junio de 2020.

${ }^{*}$ PhD, profesor de la Facultad de Filosofía, director del CREEI (Caribbean Research Ethics Education Initiative) del Programa Fogarty en la Universidad Autónoma de Querétaro, correo: bobwvsc@yahoo.com.

${ }^{* * *} \mathrm{PhD}$ en Bioética y Jurisprudencia Médica. Investigadora titular del Instituto de Investigaciones Jurídicas de la UNAM. Este trabajo es parte del proyecto de investigación "Tecnologías genéticas en la reproducción humana asistida: Acceso a la salud y al beneficio del avance científico", núm. IG300520 del Programa de Apoyo a Proyectos de Investigación e Innovación Tecnológica (PAPIIT) en la UNAM, correo: mariama@unam.mx, ORCID: https://orcid.org/0000-0003-4324-4083. 
ROBERT T. HALL / MARÍA DE JESÚS MEDINA ARELLANO

\section{Abstract:}

In this paper we analyze the social aspects on the latest moratorium on germline gene editing proposed by scientists in the journal Nature. We assert that research should not be based on public opinion consensus, but on scientific evidence. Basic science research on animals could initially be enough to later conduct research on human embryos. This is a moral judgment; the decision is based on evidence and should be taken by persons who understand science, and not by public opinion. The point of any moratorium is to move forward cautiously, but not to limit progress. Therefore, the social implications mentioned in this moratorium are limiting and may stigmatize scientific innovation.

\section{Keywords:}

Gene Editing, Germline Research, Moratorium, Consensus, Public Opinion. 
SOBRE LA ÉTICA DE UNA MORATORIA...

SUMARIO: I. Introducción: edición genética y llamados a moratorias. II. Discrepancias éticas. III. Tres pautas relevantes. IV. Implementación. V. Reflexiones finales. VI. Referencias.

\section{INTRODUCCIÓN: EDICIÓN GENÉTICA Y LLAMADOS A MORATORIAS}

En 2015, la aplicación de la edición genómica en humanos para modificar la línea germinal fue central en la discusión académica, en este tema. Esto a raíz del uso de tecnologías como TALENs y, más recientemente, CRISPR/Cas ${ }^{-1}$ una herramienta de edición genética que por su eficiencia y bajo costo es fácil de incorporar en protocolos de ciencia básica en embriones humanos. ${ }^{2}$ Es la primera vez, que se llamaba a una moratoria a consecuencia del anuncio del primer grupo de científicos en China, quienes anunciaban que habían editado genes en embriones humanos en la línea germinal. ${ }^{3}$ En este mismo año, se convocó la Primera Cumbre Internacional sobre Edición del Genoma Humano, por la Academia de Ciencias y Medicina de Estados Unidos, en donde las principales conclusiones fueron: 1) continuar con la investigación en ciencia básica, y 2) no proceder a la aplicación clínica con fines de reproducción humana. ${ }^{4}$ Por otro lado, premios nobel por separado, Lanphier ${ }^{5}$ y Baltimore, ${ }^{6}$ se

1 Véase: "Declaración sobre Edición Genética Humana del Grupo Hinxton," 2015, disponible en: $h t t p: / / w w w . h i n x t o n g r o u p . o r g / H i n x t o n 2015$ Statement.pdf(fecha de consulta: 24 de agosto de 2020).

2 Cyranoski, D. y Reardon, S, "Chinese scientists genetically modify human embryos", Nature News, 2015, disponible en: https://www.nature.com/news/chinesescientists-genetically-modify-human-embryos-1.17378.

3 Chan, S. et al., "Edición genética: Punto de no retorno," Nexos, núm. 498, 2019, disponible en: https://www.nexos.com. $m x / ? p=42688$ (fecha de consulta: 24 de agosto de 2020).

4 National Academy of Sciences, "International Summit on Human Gene Editing: A Global Discussion", 2016, disponible en: https://www.ncbi.nlm.nih.gov/ books/NBK343651/ (fecha de consulta: 24 de agosto de 2020).

5 Lanphier, E., et al., "Don't Edit the Human Germ Line”, Nature News, núm. 519, núm. 7544, 2015, p. 410.

6 Baltimore, D. et al., "A Prudent Path Forward for Genomic Engineering and Germline Gene Modification”, Science, núm. 348, vol. 6230, 2015, pp. 36-38. 
pronunciaban por una moratoria en el ámbito de la investigación en embriones humanos y su aplicación en reproducción. A la par, grupos internacionales invitaban a un llamado a la prudencia, es decir, a evitar la obstrucción de la investigación en ciencia básica de edición genética en embriones humanos, tal y como lo señalaron en la Declaración del Grupo Hinxton (2015):

14. Las sociedades tienen la autoridad para regular la ciencia y los científicos tienen la responsabilidad de obedecer la legislación. Sin embargo: 14. Cualquier limitación de la investigación científica debe ser derivada de preocupaciones razonables sobre riesgos que sean demostrables de daños a personas, instituciones de la sociedad, o la sociedad en su conjunto. Los políticos deben abstenerse de limitar la investigación científica a menos que haya una justificación sustancial para hacerlo que vaya más allá de los desacuerdos basados únicamente en convicciones morales divergentes. ${ }^{7}$

Sin embargo, en noviembre de 2018, a unas horas de que comenzara la segunda edición de la Cumbre Mundial sobre Edición Genética Humana en Hong Kong, se anunciaba que ni las recomendaciones ni discusiones coadyuvaron, y que se había ya aplicado esta tecnología con la finalidad de reproducción humana en China. Fue el "científico" He Jiankui —entre comillas, porque parte de lo que presentó da cuenta de la carencia de responsabilidad en ética de la investigación científica-, reportaba a través de un video en YouTube, que había utilizado CRISPR/Cas9 para reproducir seres humanos inmunes al VIH. ${ }^{8}$ En el marco del sensacionalismo de las redes, se circulaba la noticia de que habían nacido las bebés genéticamente modificadas, Lulú y Nana, señalado como un "regalo hermoso y puro" para los padres de las niñas y para la sociedad en general. ${ }^{9}$

7 Op. cit., nota 3.

8 De Miguel Beriain, I., “¿Modificar o no modificar el genoma de nuestra descendencia? Algunos comentarios a raíz de la Declaración del Comité de Bioética de España sobre la edición genómica en humanos," Revista Bioética y Derecho. Perspectivas Bioéticas, núm. 47, 2019.

9 Pascual, V., "El científico chino que modificó los genes de dos bebés admite otra fecundación con embriones alterados", El país, 2019, https://elpais.com/ elpais/2018/11/28/ciencia/1543381113_429352.html (fecha de consulta: 24 de 
SOBRE LA ÉTICA DE UNA MORATORIA...

En el marco de la cumbre la condena fue enérgica contra $\mathrm{He}$, y una vez terminada dicha reunión, el grupo de organizadores preparó un reporte repudiando las actividades anunciadas por He Jiankui, en donde básicamente se hacia un llamado a conducirse con las mejores prácticas éticas y estándares internacionalmente reconocidos en el área de la investigación científica. ${ }^{10}$ Dado que es importante reconocer los riesgos de llevar a cabo esta investigación, como por ejemplo, lo que hoy sabemos son los resultados no deseados, como podría ser el llamado "mosaicismo". ${ }^{11}$ La UNESCO ha llevado un trabajo muy importante con relación a deliberar públicamente sobre este tema, adoptando posiciones públicas y declaraciones internacionales ${ }^{12}$ que son un referente para la adopción de cualquier política pública a nivel global. ${ }^{13}$

En el mes de marzo de 2019, de nueva cuenta, otro grupo de científicos emitía un llamado a una moratoria similar a aquella elaborada en 2015 a raíz del primer ensayo preclínico de ingeniería genética en embriones humanos. En esta ocasión, y como reacción al escandalo de Hong Kong, un grupo de científicos publicaron en la revista Nature el comentario titulado: "Adopción de una moratoria

agosto de 2020).

10 National Academy of Sciences, "Second International Summit on Human Genome Editing: Continuing the Global Discussion: Proceedings of a Workshop-in Brief", 2019, https://www.ncbi.nlm.nih.gov/books/NBK535994/ (fecha de consulta: 24 de agosto de 2020).

11 Mosaicismo o mosaico genético, se trata de una alteración genética en la que, en un mismo individuo, coexisten dos o más poblaciones de células con distinto genotipo. Respecto de las gemelas editadas por He Jiankui y esta posible alteración, véase: Rosenbaum, L. "The future of gene editing-toward scientific and social consensus", N Engl J Med, vol. 380, núm. 10, 2019, pp. 971-5.

12 UNESCO, "Declaración Universal del Genoma Humano y los Derechos Humanos", 1997, disponible en: http://portal.unesco.org/es/ev.php-URL_ID=13177\&URL_ $D O=D O \_T O P I C \& U R L \_S E C T I O N=201 . h t m l$ (fecha de consulta: 24 de agosto 2020).

13 Véase: UNESCO “Grupo de expertos de la UNESCO pide la prohibición de "edición” del ADN humano para evitar inmoral manipulación de los rasgos hereditarios", disponible en: https://es.unesco.org/news/grupo-expertos-unesco-pide-prohibicion-edicion-del-adn-humano-evitar-inmoral-manipulacion (fecha de consulta: 24 de agosto 2020). 
en la edición del genoma heredable", del cuál resaltamos tres elementos del llamado, consistentes en la invitación a adoptar: ${ }^{14}$

Moratoria global. Consistente en no llevar al ámbito clínico la edición genética, es decir, con fines reproductivos. Dado que "se trata de una línea que no se debería de cruzar por ningún motivo o propósito". Puesto que no podemos diferenciar "mejoramiento genético", del alivio de enfermedades genéticas incurables, al momento. Ambas finalidades loables y útiles para el avance de esta área del conocimiento, sin embargo, al parecer no es así en términos de la moratoria, puesto que otorgan mayor valor ético a la segunda y descartan el mejoramiento.

Régimen de vigilancia regulatoria voluntaria. En este punto, se invita a no solamente adoptar un marco jurídico específico, dado que señalan que las autoridades sanitarias encargadas de aprobar ensayos clínicos tomando en consideración seguridad y eficacia, no siempre lo hacen de una manera "sabia", es decir, no están preparados para lidiar los cuestionamientos fundamentales (sin señalar cuáles son éstos, ni tampoco qué significa actuar de manera "sabia"). De igual manera, señalan que el registro de actividades de manera voluntaria por parte de los gobiernos en el mundo fomentará mejores prácticas, dado que no se trata de un documento que pretenda prohibir de manera total estas prácticas, sin embargo, creemos que el simple hecho de adherirse a un documento internacional "voluntario o no", implica aceptar la limitación, por tanto, tampoco creemos que sea el camino para avanzar en el área, existen otros caminos para fomentar responsabilidad en la investigación. ${ }^{15}$

Consenso social. Señalan que "La edición de la línea germinal no debe usarse a menos que haya un amplio consenso social". Por ejemplo, mencionan que las personas con diferencias genéticas o discapacidades pueden experimentar estigmatización y discriminación. Grupos religiosos y otros probablemente encontrarán la idea de rediseñar la biología fundamental de la humanidad moralmente

14 Lander, E. S. et al., "Adopt a moratorium on heritable genome editing," Nature Publishing Group, 2019.

15 Véase Luna, F., "Edición genética y responsabilidad”, Revista Bioética y Derecho. Perspectivas Bioéticas, núm. 47, 2019. 
SOBRE LA ÉTICA DE UNA MORATORIA...

problemática. Y continúan señalando que el acceso disímil a la tecnología podría aumentar la desigualdad. Este pronunciamiento al "consenso social", se entiende como llamado a una consulta pública y nos parece peligroso y poco viable, independientemente de que el "consenso" en sociedades plurales en donde existen distintas visiones éticas, culturales, religiosas, respetuosas de los derechos humanos en su diversidad, no se rigen por las mayorías, sino por democracias deliberativas que toman en consideración la variedad de perspectivas éticas de la comunidad en su conjunto y se toman en serio el respeto a los derechos fundamentales desde las diferencias. ${ }^{16}$

Las moratorias mencionadas son dúctiles y problemáticas. En principio, la naturaleza de una moratoria como temporal implica que no habrá una prohibición permanente (pero existe ya una limitante en esta postura) y eventualmente van a ocurrir ensayos clínicos, por lo que sostienen que argumentos a favor de una prohibición absoluta no están en la ecuación, sin embargo, resulta cuestionable esta postura dado que una limitante es llamar a moratoria en sí misma, es irrelevante sostenerla, ya que se seguirá llevando a cabo la investigación, tal y como lo mostró el caso de He Jiankui.

Como señalamos, la moratoria en sí misma es una propuesta ética limitante, ya que se trata de una recomendación de no acción con el propósito de evitar daño a seres humanos, y el genoma humano ensimismo. Los argumentos presentados a favor de una prohibición absoluta no son la solución, dado que, a mayor avance de la ciencia básica, la aplicación clínica no se hará esperar. ${ }^{17}$ La pregunta relevante en la que tenemos que pensar, es: ¿Cómo queremos que ocurra la aplicación clínica de la ingeniería genética humana? Al momento, la propuesta de moratoria temporal no serviría en la disminución de los conflictos de interés de la propia ciencia, dado que las y los científicos en el mundo seguirán llevando a cabo investigación con la

16 Véase: Morrison, M. y Saille, S. de, "CRISPR in Context: Towards a Socially Responsible Debate on Embryo Editing", Palgrave Communications, núm. 5, vol. 1, 2019, pp. 1-9.

17 Por ejemplo, la última sofisticación de la tecnología en cuanto a generar cadenas de ADN específicas, véase: Anzalone, A. V. et al., "Search-and-Replace Genome Editing Without Double-Strand Breaks or Donor DNA", Nature, núm. 576, vol. 7785, 2019, pp. $149-157$. 
finalidad de obtener una aplicación. Los cuestionamientos éticos importantes son la evaluación de riesgos y seguridad de las y los sujetos que serán incluidos en ensayos clínicos para la investigación sobre edición de genes en la línea germinal.

Es evidente en el caso de He Jiankui, que existen deseos de las y los científicos de adquirir fama internacional por ser los primeros en tener éxito en esta práctica. ${ }^{18}$ Otro caso similar que podemos mencionar es el ocurrido en abril de 2016, en México, cuando nació en Guadalajara el primer bebé con ácido desoxirribonucleico (ADN) de tres individuos diferentes. ${ }^{19}$ La operación se realizó para evitar que un bebé heredara una enfermedad que, de lo contrario, se transmitiría a través del ADN mitocondrial materno en el Centro de Fertilidad New Hope. ${ }^{20}$ Fue hecho en México, sin adecuada vigilancia ética, ni observancia en la regulación mexicana, como ya se advertía anteriormente, la carencia de regulación específica combinada con el precario seguimiento ético fomenta malas prácticas. ${ }^{21} \mathrm{~A}$ consecuencia de esas prácticas, se generaliza la percepción de la ciencia local proveniente de países en desarrollo, perpetuando así la errónea percepción sobre la ciencia que se lleva a cabo en estos países. ${ }^{22}$

Estos deseos de las y los científicos de ser pioneros en llevar a cabo innovación en la investigación y aplicación de ingeniería genética en humanos pone latente el hecho de que la respuesta a una práctica responsable en ciencia básica y su futura aplicación clínica

18 Véase Santillán-Doherty, P. et al., "Considerations on Genetic Engineering: Regarding the Birth of Twins Subjected to Gene Edition", Gaceta Médica de México, núm. 156, 2020, pp. 51-57.

19 Reardon, S., “Genetic Details of Controversial Three-parent Baby'Revealed," Nature News, núm. 544, vol. 7648, 2017, p. 17.

20 Palacios-González, C. y Medina-Arellano, M. J., "Mitochondrial Replacement Techniques and Mexico's Rule of Law: on the Legality of the First Maternal Spindle transfer case. J Law Biosci", Journal of Law and the Biosciences, vol. 4, núm. 1, 2017, pp. 50-69.

21 Chan, S. y Medina-Arellano, MdJ., "Genome Editing and International Regulatory Challenges: Lessons from Mexico," Ethics, Medicine and Public Health, núm. 2, vol. 3, 2016, pp. 426-434.

22 Chan, S. et al., "Mitochondrial Replacement Techniques, Scientific Tourism, and the Global Politics of Science", Hastings Center Report, núm. 47, vol. 5, 2017, pp. 7-9. 
SOBRE LA ÉTICA DE UNA MORATORIA...

no puede ser motivo de una moratoria, sino de una efectiva vigilancia ética y jurídica con los estándares internacionales existentes. Sin embargo, la comunidad científica internacional insiste en llamados necios a una moratoria, cuando lo que necesitamos son reglas flexibles que evalúen el riesgo caso por caso para que el avance suceda con vigilancia adecuada, cumpliendo con las normas éticas existes. Ejemplos del enorme interés y posibilidad de trasladar la ingeniería genética a la cama de los pacientes está frente a nosotros, por ejemplo, en Rusia y otras partes del mundo esto ya está sucediendo y la moratoria no parece ser un obstáculo, ${ }^{23}$ y por tanto las reglas éticas de la investigación científica vigentes operan como un semáforo efectivo ante comités de ética establecidos.

\section{DISCREPANCIAS ÉTICAS}

Nuestro análisis en adelante está dirigido a examinar en detalle los puntos relativos a las consideraciones "éticas, morales y sociales" presentadas en el comentario publicado en Nature por Erick Lander et al. (2019). Creemos que los puntos éticos mencionados en ese apartado están más o menos fuera del ámbito especifico de la moratoria y por lo tanto son irrelevantes para la propuesta que formulan. Las preocupaciones ahí establecidas son relevantes al asunto en general de la practica clínica generalizada de la edición de genes, pero no específicamente a la propuesta de una moratoria en la investigación científica básica. En su lugar, argumentaremos que sería más efectivo y consistente tomar en consideración y cercana atención a los requisitos y estándares internacionales establecidos, ${ }^{24} \mathrm{de}$

23 Cyranoski, D., "Russian Biologist Plans more CRISPR-Edited Babies", Nature, núm. 570, vol. 7760, 2019, pp. 145 y 146.

24 Por ejemplo, la Declaración de Helsinki. En recientes fechas el Comité de expertos de la Organización Mundial de la Salud (OMS) emitió recomendaciones sobre el desarrollo de estándares y gobernanza global respecto a la edición genética humana, no será motivo de nuestra reflexión en este trabajo, se puede acceder a esta recomendación en: "Helsinki Declaration of WMA - Ethical Principles for Medical Research in Humans", World Medical Association, Francia, Ferney-Voltaire, 2013, disponible en: http://www.wma.net/en/30publications/10policies/b3/index. 
ahí podremos seguir reflexionando en el cómo se deben implementar las guías éticas a la luz de los avances en el área de la edición genética humana y qué se debe hacer al final y después del avance de la ciencia básica en embriones humanos, para estar en condiciones de aplicar ensayos clínicos con fines reproductivos y no meramente de investigación. Comenzamos con cada uno de los puntos mencionados en el comentario:

\section{Discriminación}

Erick Lander (2019) y sus colegas sugieren que "individuos con diferencias o discapacidades genéticas podrían experimentar estigmatización y discriminación". Esto podría ser una consideración para cualquiera persona, o pareja, que está contemplando el uso de la tecnología para reproducir un descendiente genéticamente vinculado libre de enfermedades o bien con condiciones genéticas favorables para el desarrollo una vida saludable. Sin embargo, si la discriminación no es propuesta como argumento para la prohibición total del uso clínico de esta nueva tecnología, esto es muy situacional y no constituye un argumento respecto a la moratoria en sí. Además, en casos de discriminación (racismo, sexismo) normalmente no deberíamos ni culpamos a las victimas de discriminación, sino a la gente que discrimina. No decimos que es inapropiado moralmente tener niños que posiblemente van a sufrir discriminación, sino que tal discriminación ensimismo es inmoral. ${ }^{25}$ Ningún uso de tecnologías genéticas para la constitución de familias debería ser prohibida por razones de discriminación, desde una perspectiva de igualdad género, el acceso a la reproducción genética para personas de la diversidad sexual no debe limitarse ${ }^{26}$ tampoco debería ser motivo de prohibición o moratoria, incluso iría en contra de los estándares y juris-

html.pdf?print-media-type\&footer-right=[page]/[toPage.

25 Bennett, R., "The Fallacy of the Principle of Procreative Beneficence", Bioethics, núm. 23, vol. 5, 2009, pp. 265-273.

26 Cavaliere, G. y Palacios-González, C., "Lesbian Motherhood and Mitochondrial Replacement Techniques: Reproductive Freedom and Genetic Kinship", Journal of Medical Ethics, núm. 44, vol. 12, 2018, pp. 835-842. 
SOBRE LA ÉTICA DE UNA MORATORIA...

prudencia internacionales en materia de protección a los derechos humanos para las familias, al menos en América latina. ${ }^{27}$

Es aquí oportuno compartir un ejemplo relevante y cercano, la hija de uno de los autores de este texto fue adoptada en 1967 en los Estados Unidos de Norteamérica; su nombre es Lauren, ella tenía un abuelo biológico afroamericano ¿Es apropiado moralmente señalar que Lauren no debería de haber sido adoptada por el riesgo social de discriminación? Sí existían riesgos, por ejemplo: Al adoptar a Lauren sus papás adoptivos fueron expulsados del departamento en el que vivían. Más tarde surgió la pregunta sobre si a Lauren se le debería dar acceso al uso de la alberca pública, si en ese entonces hubiera sido necesario el consenso público, habría sido muy probable que la adopción y acceso a constituirse en familia se les prohibiera. De hecho, también así lo apunto un profesor de ética, es decir, señalo que una niña negra iba a ser victima de discriminación debido a su herencia genética, sin importar quiénes sean sus padres adoptivos.

Según el New York Times, la adopción de Lauren fue una de las primeras adopciones de una niña negra por padres blancos. ${ }^{28}$ En aquel entonces, era muy probable que el consenso social podría haber conducido a una prohibición de la adopción interracial. Si la posibilidad de discriminación social basada en la herencia genética es un argumento en contra de la adopción, entonces a los negros o los judíos (o a los americanos y los mexicanos) no se les debería permitir adoptar hijos. La pregunta es si el gobierno debe prohibir participación en investigaciones genéticas, limitando la libertad de elección de las y los participantes, debido a los riesgos sociales o deberíamos continuar los esfuerzos para cambiar las condiciones sociales que crean estos riesgos. El argumento para poner limites en la libertad basado en consenso social es equivocado.

Por supuesto, las y los participantes en experimentos genéticos deben considerar los riesgos sociales. Y es apropiado que el gobierno insista en que sean informados sobre los riesgos y benefi-

27 Véase: Corte IDH, Atala Riffo y niñas vs. Chile, 2011, disponible en: http:// www.corteidh.or.cr/cf/jurisprudencia2/ficha_tecnica.cfm?n Id_Ficha=196\&lang=es.

28 Klemesrud, J., "Integration am the Family Level: Whites Adopt Negro Children”, New York Times, 1967. 
cios. Esto es lo que significa el proceso de consentimiento informado y ya se encuentra en la legislación vigente. Pero la aceptación o no de riesgos sociales es un derecho de las y los participantes no del gobierno. No debe formar parte de una moratoria. Algunas veces olvidamos que el servicio médico, incluyendo prácticas nuevas y de investigación, son un contrato. El médico tiene algo que ofrecer y el paciente tiene la oportunidad de aceptar o rechazar la oferta. Las razones sociales a favor o en contra de la experimentación genética forman parte de las consideraciones de las personas para aceptar o rechazar participación en un experimento. La tarea del gobierno es controlar la práctica médica, es decir, controlar lo que deberían ofrecer, no lo que las personas deberían aceptar o rechazar. Por lo tanto, un comité de ética de investigación debería decir cuál o cuáles experimentos son médicamente de algo riesgo y no deberían ofrecerse. La aceptación de un tratamiento o procedimiento experimental es prerrogativa del paciente. Algunas tomamos riesgos: algunas otras no. Algunas personas fuman, otras no. La toma de riesgos es un derecho individual. El gobierno puede proteger este derecho al insistir en que las personas estén completamente informadas (tanto como sea posible) antes de tomar una decisión. Pero esto no le quita la decisión al paciente o a la persona sujeta de investigación.

\section{Efectos psicológicos}

El temor de que "los niños con ADN editado puedan verse afectados psicológicamente de manera perjudicial" es situacional de la misma manera. Dado que no especifican exactamente qué efectos perjudiciales tienen en mente, pero esto seguramente dependerá de cómo los padres críen y eduquen a sus hijos. La infancia criada en condiciones de pobreza a menudo se ve afectada psicológicamente, pero las familias pueden compensar esto. Los padres que contemplan el uso de la tecnología moderna para eliminar una condición médica heredable deberían considerar esto, pero de ninguna manera está asegurado que sus niños van a verse afectados psicológicamente. ${ }^{29}$

29 Kleiderman, E. et al., "The 'Serious' Factor in Germline Modification”, Journal of Medical Ethics, núm. 45, vol. 8, 2019, pp. 508-513. 
SOBRE LA ÉTICA DE UNA MORATORIA...

\section{Presiones sociales}

El comentario también sugiere que "los padres podrían ser sometidos a una poderosa presión de compañeros y de mercadeo para mejorar a sus hijos". Pero la presión social para hacer un mal uso de un procedimiento médico, como puede ser el caso de la cirugía plástica, no es razón para prohibir su uso benéfico. "Abusus non tollit usum" es una máxima medieval —el abuso no prohíbe el uso- la posibilidad de abuso no es argumento en contra al uso apropiado. ${ }^{30}$

\section{Objeciones religiosas}

En el comentario de Nature también se afirma que "muchos grupos religiosos y otros probablemente encuentren la idea de rediseñar la biología fundamental de los seres humanos moralmente preocupantes". Sin embargo, como sucede con otras cuestiones sociales, creemos que las opiniones religiosas de algunas personas no deben limitar la libertad de otras religiones ni de personas sin religión, es decir, de la comunidad secular. La iglesia católica, por ejemplo, está opuesta a cualquier tecnología de reproducción que no es "natural" (en los términos que el catolicismo), pero esto no cuenta en contra de la libertad de otros para usar o no anticoncepción en la planificación familiar. Desde hace más de cuatro décadas nos hemos reproducido de muchas maneras, diferentes a como las haya querido cualquier "Dios", y hemos de esta manera beneficiado a la constitución de familias diversas en generaciones pasadas y presentes. ${ }^{31}$

\section{Desigualdad de oportunidades}

La propuesta de una moratoria también predice que "el acceso desigual a la tecnología podría aumentar la desigualdad" porque es-

30 Koplin, J. J. et al., "Germline Gene Editing and the Precautionary Principle", Bioethics, núm. 34, vol. 1, 2019, pp. 49-59.

31 Véase: Palacios-González, C. et al., "Multiplex Parenting: IVG and the Generations to Come", Journal of Medical Ethics, núm. 40, vol. 11, 2014, pp. 752-758. 
taría disponible solo para los ricos. Esto es verdad, pero creemos que esto es un argumento muy débil respecto al progreso médico. El acceso desigual al progreso de cualquier tipo es casi siempre el caso y existen factores sociales más poderosos que aumentan desigualdad social mucho más que la biotecnología, por ejemplo, la herencia de una fortuna, o bien, el acceso a educación superior. Las y los autores de la propuesta de moratoria son quizás los beneficiarios de acceso desigual a la educación y algunos son profesores en universidades que aumentan la desigualdad de oportunidades.

Encontrar de nueva cuenta esta argumentación es interesante y tampoco es nueva, esta idea fue promovida por primera vez en un libro por bioeticistas influyentes en los Estados Unidos. ${ }^{32}$ Todos estos bioeticistas quienes imparten clases en universidades prestigiosas en donde se ofrece educación excepcional y, en última instancia, acceso a tecnología avanzada para personas de clases media y alta. Si no debemos aumentar la desigualdad social puesto que se trata de un valor ético, entonces, estos bioeticistas no deberían ser profesores en estas universidades que aumentan la desigualdad social y no son accesibles para toda la población, y no lo serán en mucho tiempo.

\section{Una subespecie humana}

Finalmente, el argumento de que "el mejoramiento genético podría incluso dividir a la humanidad en subespecies" nos parece un intento de provocar miedo sin evidencia de su probabilidad o sus consecuencias, que son los criterios estándares de la gestión de riesgos. Creación de una raza superior fue rechazado desde la segunda guerra mundial. Esta es una pendiente resbaladiza que no se desliza.

Aunque las posibilidades de discriminación, efectos psicológicos y presiones sociales pueden ser consideraciones personales, no son factores inevitables con el uso de la tecnología en cuestión, sino factores situacionales que dependen de la sociedad, la cultura y las

32 Véase: Buchanan, A. et al., From Chance to Choice: Genetics and Justice, Nueva York, Cambridge University Press, 2000. 
SOBRE LA ÉTICA DE UNA MORATORIA...

personalidades de las personas que considerarían el uso de la tecnología. Además, estos temores aplican por igual a edición de genes somáticos. La idea de una moratoria en la edición del genoma hereditario ya ha sido aceptada en principio, por supuesto, con ciertas condiciones. Así que estas consideraciones mencionadas en el comentario de Nature y que hemos analizado son consideradas irrelevantes para la propuesta de avance responsable.

Los temas relativos a las objeciones religiosas, menoscabo de igualdad de oportunidades y el desarrollo de una subespecie humana, si fueran moralmente determinativas, constituirían argumentos para una prohibición total de la ingeniería genética humana y por eso son irrelevantes a la idea de una moratoria de la edición en la línea germinal. La discusión sobre qué debe y no debe ser prohibido totalmente no ayuda mucho. Si se debe prohibir la edición de genes humanos totalmente, la pregunta sobre la moratoria no es relevante, sin embargo, creemos que la solución nunca será la prohibición, sino que una adecuada vigilancia ética y regulación flexible en la investigación científica y clínica de novedosas terapias genéticas. $^{33}$

\section{TRES PAUTAS RELEVANTES}

Proponemos consideraciones más específicas para considerar el punto de una moratoria en la edición del genoma hereditario. Creemos que una mayor consideración de los aspectos éticos de la moratoria debe ser enfocada en las pautas establecidas por la Declaración de Helsinki (OMS, 2013) y las pautas éticas del Consejo de las Organizaciones Internacionales de Ciencias Médicas (2016). Usamos estos códigos internacionales para explicar las condiciones en las que se deben permitir los ensayos clínicos y organizamos los siguientes pensamientos respecto a los requisitos éticos específicos de seguir adelante después de una moratoria razonable.

La moratoria propuesta está basada en la suposición de que sí existe un acuerdo sobre un principio ético muy general: No experi-

33 Medina-Arelano, M. J., Regular para Innovar: Células Troncales en México. Fronteras entre la ciencia, la bioética y el derecho, México, Fontamara, 2018. 
mentación en ensayos clínicos con seres humanos hasta que la evidencia en ciencia esté desarrollada lo suficientemente para estar en condiciones razonables y seguras, y así evitar errores. Dado esto, los códigos internacionales sobre ética de investigación llaman particular atención a tres puntos esenciales para la aprobación o no de ensayos clínicos: 1) el análisis de riesgos y beneficios, 2) consentimiento informado y 3 ) la confidencialidad de información personal.

\section{Consentimiento informado}

¿Cómo podemos asegurarnos de que los pacientes realmente entiendan los riesgos y beneficios? Hay personas a las que les gusta 0 están dispuestas a aceptar riesgos y existen otras personas que no toman riesgos en absoluto. Esto forma parte de su elección, de igual manera es parte de los requisitos del proceso de consentimiento informado. El problema de la ética de investigación es ¿Cómo podríamos asegurarnos de que el consentimiento de un sujeto de experimentación está realmente informado y válido? Todavía tenemos mucho campo desconocido respecto a estos avances científicos, y tenemos que desarrollar los mejores procedimientos que se puedan para asegurar que la gente que participa en experimentos otorga su consentimiento realmente informado. Probablemente siempre habrá héroes en la medicina como Jesse Gelsinger quien tomó el riesgo de un procedimiento genético y murió. Pero, como demostró la tragedia de Gelsinger, hay más que podemos hacer para mejorar el proceso de investigación responsable (incluso especialmente para evitar conflictos de intereses). Profesionistas en el área de consejería genético han desarrollado habilidades para ayudar a personas contemplando estas decisiones. El desafío de investigación respecto a la edición del genoma hereditario es colosal y se necesita que el profesional de la salud y de investigación estén involucrados en la complejidad que representa el proceso de obtención de consentimiento informado en la práctica clínica de tecnologías de innovación genética. $^{34}$

34 Véase Holzer, F. y Mastroleo, I., "Innovative care in Latin America: definition, 
SOBRE LA ÉTICA DE UNA MORATORIA...

\section{Confidencialidad de la información}

¿Cómo podemos proteger la confidencialidad de la información médica a la vez de que reconocemos que será importante realizar un seguimiento de la edición somática y de la línea germinal? Será necesaria la transparencia en el intercambio de información para evaluar los riesgos de ensayos clínicos. Los autores de la moratoria propuesta enfatizan un acuerdo científico y ético para seguir adelante con ensayos clínicos después de levantar la moratoria. Y mencionaron la monitoria previa de los grupos de investigación mencionados al inicio de este texto. Aunque, lo más importante es recalcar sobre la necesidad de intercambio de información científica sobre éxitos y fallos, esto resulta obvio, ya que es esencial para no permitir la innecesaria repetición de investigaciones fútiles. Sin embargo, el intercambio de información arriesga que pueda ser divulgada la información privada sobre individuos en contra de su derecho a la privacidad, pero creemos que podemos balancear los riesgos y beneficios en la divulgación de cierta información, sin afectación. Quizás se pueda desarrollar un registro internacional con suficiente información científica para futuras investigaciones sin revelar las identidades de los pacientes por medio de vigilancia internacional. La participación en este intercambio de información confidencial por parte de las y los investigadores debe ser un requisito indispensable en la aprobación de ensayos clínicos.

\section{Riesgos y beneficios}

¿Cómo evaluamos los riesgos y beneficios de los ensayos clínicos que involucra la edición del genoma hereditario? Creemos que se puede utilizar el principio de precaución aplicado caso por caso. El principio de precaución es muy mal entendido. Muchas comentaristas (incluyendo bioeticistas) piensan que la precaución significa que, si alguien tiene dudas sobre los riesgos de una investigación,

justification and ethical principles", Controversies in Latin American Bioethics, Spinger, 2019, pp. 145-176. 
esto debería ser suficiente para desaprobarla o prohibirla. Esta interpretación subjetiva y no es lo que sostiene el principio.

El principio de precaución consiste en que, si existe evidencia de daño o peligro, a pesar de que esta evidencia no cumple con los estándares de prueba científica (de los ensayos clínicos con grupos de control y hay más que un $5 \%$ de probabilidad de error), las autoridades tienen el derecho de limitar o no aprobar, incluso prohibir, la actividad hasta que el patrocinador o investigador demuestre que la investigación es suficientemente segura o hasta que el gobierno determine que es segura.

Por ejemplo, los pediatras han sostenido que la hormona de crecimiento bovina que se encuentra en los productos lácteos tiene efectos poco saludables en las niñas pequeñas al provocar la madurez sexual temprana (menstruación y desarrollo de los senos a la edad de 10 a 12 años). Esto no se ha demostrado mediante experimentos controlados, pero la experiencia colectiva de los pediatras es que los efectos desaparecen cuando los padres dejan de dar a las niñas los productos con la hormona. La prohibición bajo el principio de precaución, sin embargo, no es permanente. Es una moratoria. Cuando se invoca el principio, el investigador de un tratamiento experimental debería demostrar que es razonablemente seguro.

Este principio tiene implicaciones legales específicas ya que ha revertido la carga de la prueba; en lugar de demostrar que un producto o actividad es dañoso, si hay evidencia, la carga queda con el patrocinador, promotor o investigador del producto o actividad. Los Estados Unidos, significativamente, ha negado adoptar acuerdos internacionales que incluyen el principio de precaución, debido a esta implicación legal. Por supuesto, la gravedad de la evidencia es un juicio humano, pero es la evidencia que cuenta, no solo una sospecha subjetiva.

El principio de precaución, entendido de esta manera, puede constituir un criterio para la aprobación del comité de ética de la investigación de experimentación genética. Según este principio, si hay evidencia de daño, un comité podría negarse a aprobar la investigación de experimentación con seres humanos o el uso clínico hasta que el investigador demuestre que es razonablemente seguro. 
SOBRE LA ÉTICA DE UNA MORATORIA...

Creemos que en este momento se necesita considerar estas pautas más especificas para la regulación de ensayos clínicos respecto a la edición genético porque hay tanto que no se sabe. El punto de la moratoria el llevar a cabo un progreso cauteloso primero en la investigación en animales y después hacia ensayos de fase I en seres humanos para averiguar los efectos y la seguridad de los procedimientos usando la nueva tecnología, dado que estamos en un estado primitivo de esta ciencia. ${ }^{35}$

Eventualmente, la moratoria será levantada. Esto debe hacerse bajo la guía de asociaciones y comités internacionales que aplicarán los requisitos éticos generales mencionados aquí con mayor precisión a la práctica de edición de genes. Al fin de cuenta esto va a ser asunto de asociaciones internacionales que van a formular pautas para tales comités y asunto de comités de la ética de investigación hospitalarios y universitarios que (uno esperaría) van a incluir una representación más fuerte de bioeticistas multidisciplinarios y del público educado que es el caso en la actualidad. Inevitablemente, al final de la moratoria tenemos que decidir caso por caso, paso por paso y comité por comité. Al levantar la moratoria, va a ser mucha experimentación en hospitales y universidades y los comités tendrán que decidir como es el caso ahora con investigaciones. Los comités de ética de investigación deben insistir que los investigadores aceptan la carga de prueba de sus actividades y mostrar la evidencia suficiente para justificar los pasos que proponen.

\section{IMPLEMENTACIÓN}

La moratoria, como señalamos al principio, se recomienda como un acuerdo voluntario por parte de los gobiernos nacionales. Con respecto a la implementación de una moratoria, en las secciones del Marco, Compromisos y Justificación de la Moratoria, los autores proponen que: "Los gobiernos declararán públicamente que no permi-

35 Véase Bogner, A. y Torgersen, H., "Precautionary Deliberation: New Technologies and the Regulatory Call for Responsible Innovation", Genome Editing in Agriculture: Between Precaution and Responsibility, núm. 7, 2019, p. 213. 
tirán ningún uso clínico de la edición de la línea germinal humana durante un período inicial de duración." Y agregan los siguientes requisitos para levantar la moratoria:

1) Aviso público de la intención de seguir adelante con los ensayos clínicos.

2) Transparencia en la evaluación nacional de las contingencias científicas y éticas.

Un amplio consenso social dentro de la nación.

Los autores reconocen que el tercer requisito es desafiante, dado que: "El consenso de la sociedad sobre la edición de la línea germinal es algo que debe ser juzgado por las autoridades nacionales, al igual que los gobiernos hacen juicios políticos sobre las opiniones de sus ciudadanos sobre otras cuestiones sociales complejas". Sin embargo, reconocemos que es importante informar a las y los ciudadanos de las naciones sobre las investigaciones en curso y la manera en cómo se adoptan las políticas públicas en las ciencias genómicas.

\section{REFLEXIONES FINALES}

Como lo vemos, la propuesta analizada es poco realista para la implementación de una moratoria. Los gobiernos ya cuentan con dificultades para formular y aplicar políticas de la bioética y el bioderecho. Los debates nacionales no resueltos sobre investigación en embriones y células madre, el aborto, planificación familiar, vacunación, y alimentos transgénicos ya abundan. Esta propuesta estimularía innecesariamente un debate político impulsado por intereses especiales y activistas sociales y religiosos. Más bien necesitamos el desarrollo de políticas ilustradas que conduzcan en lugar de seguir el consenso público.

Las recomendaciones contenidas en la propuesta de la moratoria para confiar en organismos internacionales reconocidos como el Observatorio de Edición del Genoma Global y la Organización Mundial de la Salud son mucho más realistas. Estas organizaciones son representativas de una diversidad de opiniones, y quizás se puedan 
SOBRE LA ÉTICA DE UNA MORATORIA...

hacerlas aun más representativas. Y no están impulsados demasiado por los intereses políticos que, en la era de las redes sociales, parecen tener dificultades irreconciliables para lograr un consenso sobre este asunto.

Por lo tanto, propongamos una mayor confianza en los organismos profesionales tanto gubernamentales (no políticos, sino administrativos) como no gubernamentales. Hemos dicho que la moratoria es en sí misma una cuestión ética. Como tal, su establecimiento y las políticas y prácticas que se implementarán cuando se levanta la moratoria son esencialmente asuntos de integridad de la investigación y conducta responsable de la ciencia. Sugerimos que, en lugar de poner el inicio de la moratoria en el ámbito de las políticas nacionales voluntarias y el cumplimiento de los requisitos para seguir adelante, sería más efectivo recurrir a los organismos gubernamentales y no gubernamentales que han estado desarrollando directrices y políticas para la conducta responsable de investigación. Desde la publicación del Informe Belmont en 1973, varios gobiernos han desarrollado oficinas de protección de sujetos humanos. Tanto la adopción como la determinación del fin de una moratoria, además del desarrollo de requisitos para los ensayos clínicos cuando se levanta la moratoria pertenecen a tales agencias. Y puesto que el asunto es más una cuestión de integridad ética de la investigación, el Consejo de Editores de Revistas Científicas podría acordar en no publicar artículos e informes de ensayos clínicos sobre edición de genes humanas germinales durante una moratoria y también a condenar públicamente experimentos clínicos irresponsables y prohibir la publicación de cualquiera otro artículo sometido por investigadores éticamente irresponsables. Los centros de bioética, de análisis regulatorio y los programas académicos también podrían unirse al compromiso de una moratoria y su implementación. En resumen, proponemos confiar en los mecanismos de desarrollo internacional para monitorear la integridad de la investigación en lugar de poner el asunto en manos de políticos que están notablemente menos informados, influidos por grupos de intereses especiales e incluso en algunos aspectos sesgados en contra de la ciencia misma.

Finalmente, contrariamente a la idea de un gran debate público, afirmamos que el llamado debe ser: 
Por el respeto a los derechos humanos: Los participantes en investigaciones tienen el derecho de decidir, bien informados, si van a aceptar riesgos a su salud y riesgos sociales o no. Es un derecho humano que no debemos someter al foro de opinión público.

Por un control responsable: Los comités de ética de investigación deben ser certificados competentes por gobiernos o por organizaciones internacionales para decidir sobre los riesgos médicos con precaución basada en evidencia. Según este principio, si hay evidencia de daño, un comité podría negarse a aprobar la investigación de experimentación con seres humanos o el uso clínico hasta que el investigador demuestre que es razonablemente seguro.

Por una implementación efectiva: Reconociendo la necesidad de mejorar el sistema, debemos confiar en órganos regulatorios gubernamentales, como la Food and Drug Administration (FDA), las agencias homologas en Europa y México, por ejemplo, para evaluar lo que las ciencias médicas deben ofrecer a la gente dispuestos para participar en tratamientos o procedimientos experimentales, en comisiones que regulan la practica de medicina y en las revistas científicas y profesionistas que deben reportar solamente investigaciones aprobados por comités certificados competentes.

\section{REFERENCIAS}

Corte IDH, Atala Riffo y niñas vs. Chile, 2011, disponible en: http:// www.corteidh.or.cr/cf/jurisprudencia2/ficha_tecnica.cfm?n Id _ Ficha=196\&lang=es.

AnZAlone, A. V. et al., "Search-and-Replace Genome Editing Without Double-Strand Breaks or Donor DNA", Nature, núm. 576, vol. 7785, 2019.

BAltimore, D. et al., "A Prudent Path Forward for Genomic Engineering and Germline Gene Modification", Science, núm. 348, vol. 6230, 2015.

Bennett, R., "The Fallacy of the Principle of Procreative Beneficence", Bioethics, núm. 23, vol. 5, 2009. 
SOBRE LA ÉTICA DE UNA MORATORIA...

Bogner, A. y Torgersen, H, "Precautionary Deliberation: New Technologies and the Regulatory Call for Responsible Innovation", Genome Editing in Agriculture: Between Precaution and Responsibility, núm. 7, 2019.

Buchanan, A. et al., From Chance to Choice: Genetics and Justice, Nueva York, Cambridge Univer-sity Press, 2000.

Cavaliere, G. y Palacios-GonzÁlez, C., "Lesbian Motherhood and Mitochondrial Replacement Techniques: Reproductive Freedom and Genetic Kinship", Journal of Medical Ethics, núm. 44, vol. 12, 2018.

Chan, S. et al., "Edición genética: Punto de no retorno", Nexos, núm. 498, 2019, disponible en: https://www.nexos.com.mx/?p=4 2688.

Chan, S. y Medina-Arellano, M. J., "Genome Editing and International Regulatory Challenges: Lessons from Mexico", Ethics, Medicine and Public Health, núm. 2, vol. 3, 2016.

Chan, S. et al., "Mitochondrial Replacement Techniques, Scientific Tourism, and the Global Poli-tics of Science", Hastings Center Report, núm. 47, vol. 5, 2017.

Consejo de las Organizaciones Internacionales de Ciencias Médicas, "International Ethical Gui-delines for Health-related Research Involving Humans," 4a ed., Genova, 2016, disponible en: https://cioms.ch/shop/product/international-ethicalguidelines-for-health-related-research-involving-humans/.

CyRANoski, D., "Russian Biologist Plans more CRISPR-edited babies", Nature, núm. 570, vol. 7760, 2019.

Cyranoski, D. y Reardon, S., "Chinese Scientists Genetically Modify Human Embryos", Nature News, 2015, disponible en: https://www.nature.com/news/chinese-scientists-genetically-modify-human-embryos-1.17378.

"Helsinki Declaration of WMA - Ethical Principles for Medical Research in Humans," World Medical Association, Francia, Ferney-Voltaire, 2013, disponible en: Http://www.wma.net/ en/30publications/10policies/b3/index.html.pdf?print-media-type\&footer-right=[page]/[toPage. 
Holzer, F. y Mastroleo, I., "Innovative Care in Latin America: Definition, Justification and Ethical Principles," Controversies in Latin American Bioethics, Spinger, 2019.

De Miguel Beriain, I., “¿Modificar o no modificar el genoma de nuestra descendencia? Algunos comentarios a raíz de la Declaración del Comité de Bioética de España sobre la edición genómica en humanos", Revista Bioética y Derecho. Perspectivas Bioéticas, núm. 47, 2019.

Declaración Universal sobre el Genoma Humano y los Derechos Humanos, Organización de las Naciones Unidas para la Investigación, la Ciencia y la Cultura, 1997, disponible en: http:// portal.unesco.org/es/ev.php-URL_ID $=13177 \& U R L_{-} D O=D O_{-}$ TOPIC\&URL_SECTION=201.html.

Kleiderman, E. et al., "The 'Serious' Factor in Germline Modification", Journal of Medical Ethics, núm. 45, vol. 8, 2019.

KLemesRud, J., "Integration am the Family Level: Whites Adopt Negro Children", New York Times, 1967.

Koplin, J.J., Gyngell, C., \& Savulescu, J., "Germline Gene Editing and the Precautionary Principle”, Bioethics, núm. 34, vol. 1, 2019.

LANDER, E. S. et al., "Adopt a Moratorium on Heritable Genome Editing", Nature Publishing Group, 2019.

LANPHIER, E. et al., "Don't Edit the Human Germ Line”, Nature News, núm. 519, vol. 7544, 2015.

LunA F., “Edición genética y responsabilidad”, Revista Bioética y Derecho. Perspectivas Bioéticas, núm. 47, 2019.

Medina-Arellano, M. J., Regular para Innovar: células troncales en México. Fronteras entre la ciencia, la bioética y el derecho, México, Fontamara, 2018.

Morrison, M. y De SAILle, S., "CRISPR in Context: Towards a Socially Responsible Debate on Em-bryo Editing", Palgrave Communications, núm. 5, vol. 1, 2019.

National Academies of Sciences, Engineering, and Medicine, "International Summit on Human Gene editing: A Global Discus- 
sion", 2016, disponible en: https://www.ncbi.nlm.nih.gov/boo ks/NBK343651/.

National Academies of Sciences, Engineering, and Medicine, "Second International Summit on Human Genome Editing: Continuing the Global Discussion: Proceedings of a Workshop-in Brief", 2019, disponible en: https://www.ncbi.nlm. nih.gov/books/NBK535994/.

Palacios-GonzÁlez, C. y Medina-Arellano, M. J., "Mitochondrial Replacement Techniques and Mexico's Rule of Law: on the Legality of the First Maternal Spindle Transfer Case. J Law Biosci", núm. 4, vol. 1, 2017.

Palacios-GonzÁlez, C. et al., "Multiplex Parenting: IVG and the Generations to Come", Journal of Medical Ethics, núm. 40, vol. 11, 2014.

PAScual, V., "El científico chino que modificó los genes de dos bebés admite otra fecundación con embriones alterados", El país, 2019, disponible en: https://elpais.com/elpais/2018/11/28/ ciencia/1543381113_429352.html.

ReArdon, S., “Genetic Details of Controversial'three-Parent Baby'Revealed”, Nature News, núm. 544, vol. 7648, 2017.

Rosenbaum, L. "The Future of Gene Editing-Toward Scientific and Social Consensus", N Engl J Med, vol. 380, núm. 10, 2019.

SAntillán-Doherty, P. et al., "Considerations on Genetic Engineering: Regarding the Birth of Twins Subjected to Gene Edition", Gaceta Médica de México, núm. 156, 2020. 